\section{Clinical trials in South Africa: Need for capacity building and training}

To the Editor: The Lancet recently highlighted the importance of prioritising clinical research in South Africa. ${ }^{1}$ However, public hospitals do not encourage young medical professionals into clinical research. A plan to revitalise clinical research in South Africa is urgently needed. ${ }^{2}$

The focus of research and development (R\&D) in South Africa is clinical trials. ${ }^{3}$ The South African Clinical Research Association (SACRA) estimates that in 2008 approximately R2.2 billion was generated through conducting internationally sponsored RCTs. ${ }^{4}$ This figure was limited by local regulatory approval times and insufficient suitable research sites. The Medicines Control Council (MCC) has recently made significant strides in reducing approval times. The deficiency in suitable trial sites must be addressed specifically by increasing capacity.

International sponsors have favoured South Africa for research as the population is genetically and socioeconomically diverse, relatively drug-naïve and in need of safe and effective therapies for a broad range of diseases. ${ }^{5}$ Moreover, South Africa has a sound regulatory framework and efficient telecommunications, stipulates mandatory good clinical practice (GCP) training with 3 yearly updates, and is widely English-speaking.

The future of clinical trials depends on many factors, including recruitment efficiency and quality data. Despite recent growth in the industry, clinical research is not recognised as a speciality with formalised training (other than GCP), and proven expertise and competence is not assessed. ${ }^{6}$ Training programmes and certification processes must be standardised, with a core curriculum and reliable accreditation. Such training would improve investor and patient confidence and promote the generation of quality data. An increase in the number of trial sites would also increase patient recruitment potential and contribute towards capacity building. Such training is neither easily defined nor easily accessible. Internationally, a Masters in Public Health is regarded as the traditional degree for clinicians interested in research. International associations offering investigator certification programmes include the American Clinical Research Professionals (ACRP), the Society of Clinical Research Associates (SoCRA) and the Drug Information Association (DIA), ${ }^{7,8}$ however, a minimal number of researchers obtain such certification.

Recently, several foreign universities have been offering master's degrees in clinical research, and the Royal Colleges of Physicians' Faculty of Pharmaceutical Medicine offers a Diploma in Pharmaceutical Medicine. In South Africa, numerous GCP courses are offered ${ }^{9}$ and specific clinical trialrelated courses are slowly emerging. The Health Science Academy offers a course entitled Introduction to Clinical Research and another in Project Management for Clinical Trials. The Wits Health Consortium recently launched a quality control course for research sites; future courses include Starting Up a Research Site. Stellenbosch University offers a postgraduate Diploma in Pharmaceutical Medicine.
Clinical research is finally starting to receive the recognition it deserves. For the industry to be regarded with academic credibility, we must generate original research in peer-reviewed journals. Editors have previously not been amenable to publishing work of this nature, but there is gradual progress in this area. Additionally, we need to focus on capacity-building conferences where we can share information with colleagues in the industry.

For clinical trials to grow, standardised training and accredited certification processes must be implemented, which would foster sponsor investment, promote patient confidence and, above all, ensure rigorous data quality and integrity - the cornerstone of the research industry.

\section{J Burgess \\ N U Sulzer}

TREAD Research/Cardiology Unit

Department of Internal Medicine

Tygerberg Hospital and

Stellenbosch University, W Cape

lesley@treadresearch.com

1. Lawn JE, Kinney MV. Health in South Africa: Executive Summary of the Series. Lancet 2009; 347: 2-6

2. Gevers W. Clinical research in South Africa: a core asset under pressure. Lancet 2009; 347 760-762.

3. Kahn M, Gastrow M. Pharmacologically active: clinical trials and the pharmaceutical industry. S Afr Med J 2008; 98(2): 114-116.

4. Richardson M-A. Focus on Africa. African Clinical Research Organisation (ACRO) Online November 2009. www.acro.co.za (accessed 17 December 2009).

5. South African Department of Health. Guidelines for Good Practice in the Conduct of Clinical Trials with Human Participants in South Africa. 2nd ed. Pretoria: Department of Health, 2006.

6. Burgess LJ, Sulzer NU. GCP accreditation - a worthwhile investment? S Afr Med J 2006; 96(3): 161-162.

7. Hartnett T. Investigator certification: A pivotal role in assuring trial quality. Clin Res 2003; 3(8): $11-16$.

8. Arant T, Soo Bang, MS, Boepple P, et al. Advancing your clinical research career through educational opportunities. The Monitor 2007; September: 19-23.

9. Emanuel S, Sulzer NU, Burgess LJ. A step-by-step guide to establishing a cardiology research unit. SA Heart 2004; June: 8-15.

\section{Surviving in the public sector}

To the Editor: I have read the latest Med-e-Mails from SAMA with increasing distress. The apparent failure of our new Minister of Health to solve the problem of enabling doctors to negotiate just salary increases, because of labour legislation, is sad indeed. The obvious anger that this has evoked among members of the profession is very serious. It is awful to hear threats of resorting to strike action once more in this essential service. We can expect that the brain drain will again accelerate. Medical and nursing staff who decide to stay in the service for love of our people will be increasingly open to burn-out and discouragement.

My experience of 48 years in the public health structures of this nation suggests that those who stay will not find help in coping from the Department of Health. Those sensitive to their neighbours' pain then often find the situation intolerable - they have to opt out for their own well-being. My own experience of that, as a gynaecologist in a rural KZN town, came in 2001. Dealing with as many as 120 child rapes per annum over a period of 10 years upset me so much that I had to pass this important and difficult work on to more junior staff with less experience. Now, with more time to consider the problem, I realise that medical staff in public hospitals must take care 